\title{
Oxidation of ion channels in the aging nervous system
}

\author{
Rahul Patel and Federico Sesti
}

Department of Neuroscience and Cell Biology

Robert Wood Johnson Medical School

Rutgers University

683 Hoes Lane West

Piscataway, NJ 08854

USA

Correspondence to:

Federico Sesti, Ph.D.

email: federico.sesti@rutgers.edu

Phone: (732) 2354032

Fax: (732) 2355038 


\section{Abstract}

Ion channels are integral membrane proteins that allow passive diffusion of ions across membranes. In neurons and in other excitable cells, the harmonious coordination between the numerous types of ion channels shape and propagate electrical signals. Increased accumulation of reactive oxidative species (ROS), and subsequent oxidation of proteins, including ion channels, is a hallmark feature of aging and may contribute to cell failure as a result. In this review we discuss the effects of ROS on three major types of ion channels of the central nervous system, namely the potassium $\left(\mathrm{K}^{+}\right)$, calcium $\left(\mathrm{Ca}^{2+}\right)$ and sodium $\left(\mathrm{Na}^{+}\right)$ channels. We examine two general mechanisms through which ROS affect ion channels: via direct oxidation of specific residues and via indirect interference of pathways that regulate the channels.

The overall status of the present studies indicates that the interaction of ion channels with ROS is multimodal and pervasive in the central nervous system and likely constitutes a general mechanism of aging susceptibility. 


\section{Introduction}

Aging is a fundamental feature of life which encompasses both physical and psychological change. The biological causes of aging are not known, but there is general consensus around the notion that its etiology is multifactorial. Theories of aging can be divided into two broad groups: those that explain aging as the result of accumulation of damage and those which see aging as the consequence of programmed-death processes. It is likely that the combined action of these two basic mechanisms shapes the aging process, with large variability between individuals.

The "free radical theory of aging", proposed by Harman in the 1950s (Harman, 1956), is one among the predominant theories of the damage group. Harman's original hypothesis posits that accumulation of reactive oxygen species (ROS) over time damages essential components of the cell eventually leading to its failure. In fact, evidence shows that reducing oxidative damage extends lifespan, whereas enhancing oxidative damage shorten lifespan in both invertebrates and vertebrates (reviewed in (Beckman and Ames, 1998; Bokov et al., 2004; Kregel and Zhang, 2007; Sohal and Weindruch, 1996)). However increasing antioxidant defenses generally does not prolong longevity beyond the species-specific maximum and in some cases it can shorten the life span (Gems and Doonan, 2009; Mockett et al., 2010; Ristow and Schmeisser, 2011). Therefore, whether reducing oxidative damage is sufficient to extend lifespan remains an open question. On the other hand, ROS act as signaling molecules in a number of physiological pathways (Droge, 2002; Forman et al., 2010; Maher, 2006; Veal and Day, 2011). This double-edged sword nature of ROS may 
explain why in certain cases antioxidants shorten lifespan. Nonetheless, the current opinion is that structural damage alone is not sufficient to account for the functional loss associated with aging and several corrective mechanisms have been proposed. One of the most popular is the "redox stress hypothesis of aging" which predicts that ROS can cause cell failure through interfering with signaling pathways and their associated components in addition to imposing direct damage thus incorporating both the beneficial and malign nature of ROS (reviewed in (Sohal and Orr, 2012)). Notwithstanding the details of the mechanisms through which ROS inflict damage, their targets offer another perspective to help us to better understand the aging process. In fact, while most of the experimental effort has focused on studying the effects of reducing oxidative damage, a comparatively small number of proteins targeted by ROS are known and studied. In this review we focus on one of them, the ion channels.

Ion channels are integral membrane proteins responsible for passive movement of ions across membranes (Hille, 2001). As such, they generate and shape electrical signals in cells while also having functions independent of their ability to conduct ions (for a review of non-conducting roles of ion channels see ref. (Kaczmarek, 2006)). The nervous system offers one of the most comprehensive examples of the importance of ion channels given the unique relationship that exist between neurons and the electrical signals they generate and exchange. It follows that oxidative modifications of ion channels by ROS has the potential to represent a major mechanism of aging vulnerability in the brain, a mechanism that may contribute to the cognitive decline characteristic of the late-phase of life. Here we examine the cases of two wellestablished substrates for ROS, the potassium $\left(\mathrm{K}^{+}\right)$and calcium $\left(\mathrm{Ca}^{2+}\right)$ channels and 
one emerging substrate, the sodium $\left(\mathrm{Na}^{+}\right)$channel. We discuss the modes through which aging-dependent oxidative processes affect these channels in the central nervous system. We review evidence showing that ROS impact ion channel function via both direct oxidation and indirect dysregulation of their signaling pathways. The general picture that emerges is one in which the interactions of ion channels with ROS is multimodal and pervasive in the brain.

\section{Oxidation of $\mathrm{K}^{+}$channels}

Direct evidence that oxidation of an ion channel can lead to functional deficits as a side effect of increased cellular oxidation during aging came from Caenorhabditis elegans (Cai and Sesti, 2009). This animal is attracted by salts, amino-acids, vitamins

etc. that are primarily detected by the ASE neurons (Bargmann and Horvitz, 1991). The sensory capacity of these cells declines with age (Cai and Sesti, 2009; Maglioni et al., 2014; Minniti et al., 2009; Wu et al., 2006), an effect due, in part, by oxidation of a cysteine residue (cys113) on a voltage-gated $\mathrm{K}^{+}$channel named KVS-1 (Bianchi et al., 2003; Cai and Sesti, 2009). When KVS-1 channels are oxidized they conduct more current and consequently affect neuronal output; in fact, transgenic animals that express a KVS-1 mutant bearing a cysteine to serine replacement (C113S) retain their sensory capacity during aging or after being exposed to acute oxidative challenges. KVS-1 is homolog to KCNB1/Kv2.1 (Rojas et al., 2008) which carries a major somatodendritic current in neurons of the hippocampus and cortex (Du et al., 1998; Murakoshi and Trimmer, 1999; Trimmer, 1991; Trimmer, 1993). KCNB1 is susceptible to redox (Cotella et al., 2012; Wu et al., 2013). When exposed to oxidants, several cysteines, 
including cys73, the equivalent of cys 113 in KVS-1, form disulfide bridges that cross-link KCNB1 subunits to each other. In vitro studies have shown that KCNB1 oligomers are poorly internalized and as a result build up in the plasma membrane. The cell responds by activating Src tyrosine kinases and c-Jun N-terminal (JNK), kinases which initiate an apoptotic program by targeting mitochondria in addition to generating more ROS (Fig. 1A). KCNB1 oligomers are present in the brains of aging mice indicating that KCNB1 is subject to a natural process of oxidation, but whether KCNB1 oligomerization is a cause of functional impairment has yet to be determined. In addition, KCNB1 can be indirectly affected by conditions of oxidative stress in the cell. Evidence shows that acute exposure of mammalian cells or primary neurons to oxidants, triggers the cytoplasmic release of zinc $\left(\mathrm{Zn}^{2+}\right)$ and calcium $\left(\mathrm{Ca}^{2+}\right)$ (McCord and Aizenman, 2013). These divalent ions initiate a series of molecular events that lead to sequential phosphorylation of KCNB1 channels by protein kinase A, apoptosis signal-regulating kinase 1, p38 MAPKdependent kinase, $\mathrm{c}$-Src tyrosine kinase, and $\mathrm{Ca}(2+) / \mathrm{calmodulin}-$ dependent protein kinase II (Aras and Aizenman, 2005; McCord and Aizenman, 2013; Norris et al., 2012; Redman et al., 2007; Redman et al., 2009; Zhou et al., 2012). Phosphorylation of the channel enhances its forward trafficking to the plasma membrane giving rise to a $\mathrm{K}^{+}$ current surge that is thought to induce apoptosis (McCord and Aizenman, 2013), (Fig. 1B). It remains to be determined whether the oxidative conditions typical of normal aging are sufficient to trigger this mechanism of apoptosis vulnerability. Nonetheless, KCNB1 surge is likely to be toxic when cellular oxidation is exacerbated as it is in certain neurodegenerative diseases. In summary KCNB1 is affected by ROS both directly and indirectly but whether these influences lead to brain dysfunction awaits 
validation in animal models. However, other $\mathrm{K}^{+}$channel types appear to be targets of ROS as well as being pervasively oxidized in the central nervous system. One of these channels is the KATP $\mathrm{K}^{+}$channel. In nature, KATP channels are heteromeric complexes formed by a pore forming subunit (Kir6.x) and a sulfonylurea receptor (SUR1 and SUR2A-B) (Clement et al., 1997; Inagaki et al., 1995) with different combinations resulting in channels with different attributes (Babenko et al., 1998; Cheng et al., 2008; Yamada et al., 1997). KATP sense variations in ATP/MgADP ratio and as such respond to metabolism changes and exert protection under certain metabolic stresses (reviewed in (McTaggart et al., 2010)). For example, during hypoxia, the closure of KATP channels acts to buffer the impact of the insult by slowing down calcium entry via depolarization of the plasma membrane (reviewed in (Rana et al., 2015)). KATP channels are generally downregulated in cellular environments subject to oxidation, including aging tissue and the Alzheimer's disease (AD) brain (Bao et al., 2013; Du et al., 2013; Liu et al., 2010; Raveaud et al., 2009; Toyoda et al., 1997; Tricarico and Camerino, 1994). Diazoxide, a specific KATP activator was shown to ameliorate hallmark lesions of $A D$ in cultured neurons and rescued memory loss in 3x-Tg-AD mice (Liu et al., 2010). Diazoxide was also shown to be protective in NSC-34 motor neurons subjected to a variety of neurotoxic insults including oxidative damage via its modulation of KATP channels (Virgili et al., 2013). Notably, KATP channels can be directly modulated by thiol-redox reactions which act to decrease the opening probability. Thus, Tricarico and Camerino showed that KATP channels expressed in skeletal muscle fibers of old rats are roughly eight times less likely to open than those in young animals (Tricarico and Camerino, 1994). Sulfhydryl group-reducing agents rescue the open probability to 
"young" values whereas sulfhydryl group-oxidizing agents, abolish channel openings, thereby demonstrating that the robust decrease of the open probability of the channel is due to modification of its thiol groups. Even though muscular KATP channels may be different from neuronal KATP channels, the fact that the former are susceptible to redox may suggest that side effect oxidation of these channels may constitute a mechanism of neuronal impairment in the aging brain.

Another important $\mathrm{K}^{+}$channel type, the calcium-activated $\mathrm{K}^{+}$channel $\left(\mathrm{K}_{\mathrm{Ca}}\right)$ exhibits a consistent pattern of dysregulation during aging. $\mathrm{K}_{\mathrm{Ca}}$ channels modulate a variety of physiological functions including cellular excitability, circadian rhythm, vasodilation, and cell proliferation (reviewed in (Vergara et al., 1998)). Studies show that $\mathrm{K}_{\mathrm{Ca}}$ channel currents are upregulated in aging tissue (Hu et al., 2001; Misonou et al., 2006; Obermair et al., 2003; Turner et al., 2015) of the nervous system, (Farajnia et al., 2015; Power et al., 2002), skeletal muscle (Tricarico et al., 1997; Vergara and Ramirez, 1997) and endothelium (Behringer et al., 2013; Feher et al., 2014). $\mathrm{K}_{\mathrm{Ca}}$ currents are also increased in the brains of murine models of neurodegeneration (for example the TgCRND8 mouse model of AD) and in mice subjected to cerebral ischemia (Gong et al., 2002; Ye et al., 2010). A theme common to all these conditions is increased oxidation. This implies that ROS may be the underlying cause of increased $\mathrm{K}_{\mathrm{Ca}}$ activity and an example of this is found in the microvasculature. The opening of small and intermediate conductance $\mathrm{K}_{\mathrm{Ca}}(\mathrm{SK}, \mathrm{IK})$ channels initiate endothelial cell hyperpolarization which spreads to the smooth muscle cells to promote their relaxation. Vascular aging is associated with reduced blood flow and SK and IK channels are major culprits for this deficit. Using specific pharmacological blockers, Behringer and colleagues found that 
SK and IK channels conduct more current in the epigastric resistance arteries of aging mice compared to that of young mice (Behringer et al., 2013). Application of hydrogen peroxide $\left(\mathrm{H}_{2} \mathrm{O}_{2}\right)$ activated $\mathrm{K}_{\mathrm{Ca}}$ channels in young animals, whereas $\mathrm{H}_{2} \mathrm{O}_{2}$ scavengers decreased $\mathrm{K}_{\mathrm{Ca}}$ current in the arteries of old animals. Similar results were obtained by Feher and colleagues who found that conducted dilation declines with age in coronary arterioles of human patients and SK and IK conductances are upregulated in those vessels (Feher et al., 2014). In summary, by conducting more current, $\mathrm{K}_{\mathrm{Ca}}$ channels present in aging endothelial cells impair vasomotor control (Behringer et al., 2013). But is endothelial $\mathrm{K}_{\mathrm{Ca}}$ upregulation due to oxidation of the channels? While this possibility cannot be ruled out, the most probable cause is likely to stem from an excess of intracellular calcium - due to a shift toward oxidation in the redox status of the cellular environment—which induces endothelial SK and IK opening. Examples of this mechanism can be found in both pathological conditions such as cerebral ischemia (Liao et al., 2010; Runden-Pran et al., 2002) and normal physiological conditions such as the aging hippocampus (reviewed in (Sesti et al., 2010)), a case that will be discussed in more detail in the section dealing with oxidation of $\mathrm{Ca}^{2+}$ channels. However, the third member of the $\mathrm{K}_{\mathrm{Ca}}$ family, the maxi conductance (BK) channel is directly susceptible to redox. Santarelli and colleagues reported that in Slo1 channels expressed in mammalian cells, oxidation of three methionines (met536, met712 and met739) increases the open probability without other tangible effects on the properties of the channel (Santarelli et al., 2006). Tang and colleagues identified a single cysteine in Slo1, cys911, that when oxidized acts to decrease the open probability of the channel (Tang et al., 2004). Accordingly, BK channels can be oxidized in vivo, even though with 
controversial results. Thus, Gong and colleagues showed that oxidants enhance BK current in inside-out patches from pyramidal neurons of the hippocampus, by increasing the open probability (Gong et al., 2000). They also found that oxidized glutathione, (GSSG) activates the channels and glutathione (GSH) reverses those effects. In a subsequent study, Soh and colleagues came to opposite conclusions (Soh et al., 2001). They found that GSSG inhibits and GSH activates the channels present in excised patches from neonatal rat hippocampal neurons. These controversial results may have several explanations. One could be found in the complex dependence of BK channels to redox in which oxidation of methionine and cysteine residues has opposite effects on the open probability (Santarelli et al., 2006; Tang et al., 2004; Zhang et al., 2006). In addition, the presence of accessory subunits may contribute to BK dependence on redox. Recently, Hu and colleagues reported that oxidative stress acts to directly decrease BK current density in sheep uterine arteries during chronic hypoxia by downregulating its $\beta 1$ accessory subunit (Hu et al., 2015). Another $\beta$-subunit of BK channel, $\beta 3$, brings redox-dependent gates that block ion permeation (Zeng et al., 2003). Further, the Gong study was carried out using cells from adult animals whereas Soh used neurons dissociated from neonatal rats. The issue is significant and deserves further scrutiny though, considering that under physiological conditions GSH and GSSG are simultaneously present in the cell and therefore variations in their ratio may have a significant effect on the cell function via BK channel regulation.

In summary, $\mathrm{K}^{+}$channels are directly and indirectly affected by increased oxidation in the cell. 


\section{Oxidation of $\mathrm{Ca}^{2+}$ channels}

Long Term Potentiation (LTP) is a major mechanism underlying learning and memory formation (Bliss and Collingridge, 1993; McNaughton et al., 1986; Morris et al., 1986). Different areas of the brain exhibit different forms of LTP. In the hippocampus, a large and transient increase in post-synaptic intracellular calcium leads to protein kinase-mediated potentiation of the $\alpha$-amino-3-hydroxy-5-methyl-4-isoxazolepropionic acid receptor (AMPAR) component of synaptic strength (Fig. 2A). The N-methyl Daspartate receptor (NMDAR) provides the major route for calcium entry (reviewed in (Malenka and Bear, 2004)). In addition, two NMDAR-independent mechanisms, that is, opening of voltage-dependent calcium channels (VDCCs) and release of calcium from intracellular calcium stores (ICS) further contribute to transient rise of free intracellular calcium during LTP (Berridge, 1998; Futatsugi et al., 1999; Johnston et al., 1992; Moosmang et al., 2005; Verkhratsky, 2002; Verkhratsky and Petersen, 2002; Wu et al., 2004). ICS release proceeds through calcium binding to ryanodine receptors (RyRs), a mechanism commonly known as calcium-induced calcium release (CICR) and activation of inositol triphosphate receptor $\left(\mathrm{IP}_{3} \mathrm{R}\right)$ via metabotropic glutamate receptors (Berridge, 1998; Berridge et al., 2000; Futatsugi et al., 1999). As the brain ages, there is a shift in the relative strength of the NMDAR-dependent and NMDAR-independent pathways which makes neurons progressively refractory to LTP induction (Barnes, 1979; Foster, 1999; Landfield et al., 1978). Studies have shown that higher frequency stimulation is necessary to induce LTP in old rodents and that LTP mainteniance is generally impaired in those animals (Foster, 1999; Hsu et al., 2002). It turns out that the increased oxidation in the cell during aging causes both progressive impairment of the 
NMDAR-dependent mechanism (Bodhinathan et al., 2010b; Robillard et al., 2011; Yang et al., 2010) and at the same time increase of free intracellular calcium via potentiation of the CICR mechanism (Bodhinathan et al., 2010a; Bodhinathan et al., 2010b; Kumar and Foster, 2004; Kumar et al., 2009; Norris et al., 1998; Oh et al., 2010; Thibault and Landfield, 1996) and according to a recent study, also of the $I P_{3} R$ mechanism (Bansaghi et al., 2014). The surplus of calcium boosts opening of SK channels, which control the onset and duration of the slow after hyperpolarization (sAHP) - a key feature of memory impairment during aging (Faber, 2010). This decrease in synaptic excitability lowers susceptibility to LTP induction (Fig. 2B). Bodhinathan and colleagues showed that reducing agents are effective in decreasing the sAHP in old but not young rats, and that blockade of RyRs or depletion of intracellular calcium stores suppressed dithiothreitol (DTT) effects, whereas DTT-mediated decrease in sAHP was not affected by inhibition of other $\mathrm{Ca}^{2+}$ pathways such as VDCCs (Bodhinathan et al., 2010a). Additionally, pharmacological agents that block SK channels or VDCCs as well as inhibition of calcium release from ICS, all act to reestablish LTP induction at low frequencies (Bodhinathan et al., 2010b; Kumar and Foster, 2004; Norris et al., 1998). In conclusion, the dysregulation of SK channels and NMDARs that takes place in aging hippocampal neurons provides another example of how ROS can indirectly influence the function of channels by affecting their mechanisms of regulation. However, SK and NMDAR are not the only channels to be affected by ROS in this process of memory impairment: treatments that inhibit the CICR mechanism have the greater effect on aging animals, thus implicating the RyR as one of the major players (Bodhinathan et al., 2010a; Kumar and Foster, 2004; Paula-Lima et al., 2014). In fact, the RyR is a well- 
established redox-sensitive channel (reviewed in (Hidalgo et al., 2004; Hidalgo et al., 2007; Lanner et al., 2010)). $\mathrm{Ca}^{2+}$ leakage through oxidation-modified RyRs has been extensively studied in muscle; for example Andersson and colleagues showed that in skeletal muscle fibers of old mice RyR1 is oxidized, cysteine-nitrosylated and lacks accessory subunit calstabin1 (Andersson et al., 2011). There is consensus that oxidative modifications of RyR1 give rise to channels that open more readily and thus leak calcium (Andersson et al., 2011; Anzai et al., 1998; Bull et al., 2007; Donoso et al., 2011; Favero et al., 1995; Hanna et al., 2014; Lanner et al., 2010; Marengo et al., 1998; Oda et al., 2015; Paula-Lima et al., 2014). However, RyR1 is not expressed in the hippocampus but RyR2 and RyR3 are, and all three RyR isoforms exhibit sequence and structural homology (Furuichi et al., 1994; Hakamata et al., 1992; Lai et al., 1992; Sharp et al., 1993; Takeshima et al., 1989). In particular, RyRs have large numbers of cysteines per subunit (roughly 100 in RyR1, (Lanner et al., 2010)), many of which are redox-sensitive (Aracena et al., 2006; Aracena-Parks et al., 2006; Voss et al., 2004). Thus, given the homology between the three RyR isoforms it appears likely that neuronal RyR2 and RyR3, like RyR1, are directly oxidable, a notion that receives support from the work of Bull and colleagues. This group showed that in single RyRs from rat brain cortex incorporated into the lipid bilayers the redox state of the receptor determines its activation by $\mathrm{Ca}^{2+}$ (Bull et al., 2003; Bull et al., 2007). They further showed that the RyR2 and RyR3 from the cortex of rat brains subjected to cerebral ischemia, and thus to increased cellular oxidation, opened more readily and thus leaked more calcium than their respective RyRs in control brains, due to S-glutathionylation of not yet identified cysteine residues (Bull et al., 2008). Additionally the $I P_{3} R$ is a putative 
player in ROS-mediated regulation of calcium release from ICS as recent evidence indicates that superoxide anion modifies thiol groups within the $I P_{3} R$ leading to sensitization of calcium release (Bansaghi et al., 2014). Elucidation of the details of the mechanism awaits follow up studies.

In summary the RyR is directly affected by shifts in the redox status of the cell. This leads to leakage of intracellular calcium which promotes decreased LTP capacity via overactivation of SK channels. Hence, LTP provides a clear example of how oxidative conditions during aging can lead to physiological impairment via modification of ion channels.

\section{Oxidation of $\mathrm{Na}^{+}$channels}

Voltage-gated sodium (Nav) channels are responsible for action potential initiation in neurons (Hille, 2001). Modifications in the synthesis and/or trafficking of Nav channels that alter their surface expression can affect the electrical excitability of the neuron even when the conducting attributes of the channel, (i.e. gating, permeation, and selectivity) are not changed. An example in this sense is provided by the Nav1.1 isoform, a pore-forming subunit broadly expressed in the brain including the hippocampus (Trimmer and Rhodes, 2004) and one of its accessory subunits, Navß2. Kim and colleagues showed that Nav $\beta 2$ is a substrate for $\beta$-secretase 1 (BACE1) and $\gamma^{-}$ secretases and that Nav $\beta 2$ processing is remarkably similar to that of amyloid precursor protein (APP) in the AD brain (Kim et al., 2007). Thus, Nav $\beta 2$ undergoes sequential BACE1 and $y$-secretase cleavage which releases a soluble intracellular domain ( $\beta 2$ ICD) which in turn, regulates Nav1.1 mRNA and protein levels (Fig. 3A). Experimental 
manipulations that act to decrease BACE1 activity diminish Nav1.1 synthesis and vice versa, increasing the activity of BACE1 augments Nav1.1 mRNA and protein levels. At the plasma membrane however, the situation is different. While neurons from BACE1null mice express low amounts of Nav1.1 current density as expected, Nav1.2 current is increased, perhaps as a compensatory mechanism for reduced surface Nav1.1 (Hu et al., 2010)). Also the neurons from mice overexpressing BACE1 exhibit low amounts of Nav1.1 current because the channel is not properly translocated to the plasma membrane (Hu et al., 2010; Kim et al., 2007; Kim et al., 2011). This BACE1 activitymediated mechanism may have profound implications for the aging of neurons in which Nav1.1-Navß2 complexes operate. Evidence shows that the activity of BACE1 is upregulated in both aging human, monkey, mouse brains and primary cells (Cai et al., 2010; Che et al., 2014; Dobarro et al., 2013; Fukumoto et al., 2004; Kern et al., 2006; Miners et al., 2010; Solas et al., 2013; Wu et al., 2012). Evidence further shows that oxidative stress is a major underlying driving force of the upregulation of BACE1 expression and activity (Brown et al., 2014; Guglielmotto et al., 2009; Guglielmotto et al., 2010; Kizuka et al., 2016; Kwak et al., 2011; Mouton-Liger et al., 2012; Tamagno et al., 2002; Tan et al., 2013; Xiong et al., 2007). Together, this evidence argues that BACE1 may act to decrease sodium current density and consequent reduction in neuronal excitability during aging (Fig. 3B). Indeed, Randall and colleagues reported that mouse hippocampal CA1 pyramidal neurons showed the tendency to be less excitable as the animals aged (Randall et al., 2012). However this hypoexcitability did not stem from a decrease in the density of sodium current, as the BACE1 mechanism would predict, but rather from a shift in the voltage-dependence of activation of the 
current toward more depolarizing voltages. Fernandes and colleagues compared the functional properties of single sodium channels in excised inside-out patches from acutely isolated CA1 neurons of young and old rats. The unitary sodium conductance was moderately decreased in old cells compared to young cells and inactivation kinetics were also altered in old neurons leading to failure of fast inactivation (Fernandes et al., 2001). Moreover, fast inactivating sodium current density is higher in hippocampal neurons from BACE1-null mice, probably due to compensatory increase in Nav1.2 expression (Hu et al., 2010). As a result neurons are more excitable and the animals susceptible to seizures, although it is important to remember that the null-mouse is not physiologically representative. On the other hand, evidence shows that the levels of Nav1.1 protein are downregulated in certain areas of the aging cerebellum. Chung and colleagues examined the expression of Nav1.1 and Nav1.2 isoforms in the rat cerebellum and detected both increased and decreased Nav1.1 and Nav1.2 expression in Purkinjie fibers and granule cells, respectively (Chung et al., 2003). Further, Nav1.1 expression was decreased in the cerebellar nuclei of aging rats compared to control adults, whereas Nav1.2 expression did not change. Notably, Nav $\beta 2$ is expressed throughout the cerebellum (Trimmer and Rhodes, 2004) and it is therefore tempting to speculate that the decrease in Nav1.1 expression reported by Chung et al. stems from increased BACE1 activity. Albeit, more evidence is needed to confirm this hypothesis, we do notice, that age-dependent downregulation of Nav isoforms and their accessory Nav $\beta$ subunits has been reported to occur in aging muscle (Huang et al., 2015).

Like the other channel types examined thus far, Nav channels are susceptible to redox. Kassmann and colleagues showed that oxidation of several methionines in the 
Nv1.2, Nav1.4, Nav1.5 and Nav1.7 isoforms act in concert to suppress inactivation (Kassmann et al., 2008). However, studies from another group show that general oxidants (tert-butyl-hydroperoxide) as well as compounds that promote lipid peroxidation (E2-isoketal) potentiate inactivation of Nav1.5 channels (Fukuda et al., 2005; Nakajima et al., 2010). These studies prompt two considerations. First, there is evidence that inactivation kinetics of sodium currents are altered in aging neurons as shown by Fernandes and colleagues. Second, only pore-forming subunits were examined in in vitro studies whereas native channels are endowed by accessory subunits. Further, heterologous expression systems often do not recapitulate native cellular environments.

In conclusion, the evidence at hand points to ROS-modulation of Nav channels as an emerging mechanism of aging vulnerability in the brain. This hypothesis awaits confirmation as well as further elucidation of the details of the mechanisms.

\section{Conclusions}

The status of current studies indicates that the interactions of ion channels with ROS are pervasive in the central nervous system and thus likely to play a determining role in the aging process and in pathological conditions characterized by exacerbated oxidation, such as certain neurodegenerative diseases. Furthermore, oxidation of ion channels is widespread, although the discussion of non-neuronal cases was beyond the scope of this review.

The number of potential interactions between ROS and ion channels is virtually infinite but cells have multiple lines of defense against the toxic effects of ROS and their 
associated damage. Nonetheless, it is likely that many more cases await to be discovered. One factor limiting the pace of experimental inquiry is that ROS can simultaneously be construed as both "good" and "bad" molecules, and this can confound the interpretation of the results. In fact, this double-edged sword nature of ROS may be at the root of the problem of why pharmacological trials using antioxidants have generally failed. Oxidative modifications of ion channels have been successfully characterized in vitro where the controlled experimental conditions make possible to establish causative correlations between specific residues in the protein and changes in function. In vivo however, the situation is considerably more complex and ascertaining whether changes in the properties of a channel are caused by oxidation requires significant experimental effort. As the case of sodium channels shows, functional modifications in a channel during aging may be influenced by several factors that are not taken into consideration when the same channel is studied in vitro, including the presence of accessory subunits in the complex, different cellular environments etc. One way to circumvent these limitations is to employ transgenic animals harboring redoxresistant channel variants. This approach was successfully used in $C$. Elegans, in which worms expressing non-oxidable KVS-1 mutant channels enabled to establish causative relationships between oxidation of the channel, changes in neuronal excitability, and animal's behavior during aging. Recent advances in mouse genetics techniques make now possible to use a similar strategy to answer crucial questions about the oxidation of channels in the central nervous system. 
Acknowledgements We thank Shuang Liu for critical reading of the manuscript. This work was supported by a NSF grant (1456675) to Federico Sesti.

\section{References}

Andersson, D.C., Betzenhauser, M.J., Reiken, S., Meli, A.C., Umanskaya, A., Xie, W., Shiomi, T., Zalk, R., Lacampagne, A., Marks, A.R., 2011. Ryanodine receptor oxidation causes intracellular calcium leak and muscle weakness in aging. Cell metabolism. 14, 196-207.

Anzai, K., Ogawa, K., Kuniyasu, A., Ozawa, T., Yamamoto, H., Nakayama, H., 1998. Effects of hydroxyl radical and sulfhydryl reagents on the open probability of the purified cardiac ryanodine receptor channel incorporated into planar lipid bilayers. Biochemical and biophysical research communications. 249, 938-42.

Aracena, P., Aguirre, P., Munoz, P., Nunez, M.T., 2006. Iron and glutathione at the crossroad of redox metabolism in neurons. Biological research. 39, 157-65.

Aracena-Parks, P., Goonasekera, S.A., Gilman, C.P., Dirksen, R.T., Hidalgo, C., Hamilton, S.L., 2006. Identification of cysteines involved in S-nitrosylation, Sglutathionylation, and oxidation to disulfides in ryanodine receptor type 1. The Journal of biological chemistry. 281, 40354-68.

Aras, M.A., Aizenman, E., 2005. Obligatory role of ASK1 in the apoptotic surge of $\mathrm{K}_{+}$ currents. Neuroscience letters. 387, 136-40.

Babenko, A.P., Aguilar-Bryan, L., Bryan, J., 1998. A view of sur/KIR6.X, KATP channels. Annual review of physiology. 60, 667-87.

Bansaghi, S., Golenar, T., Madesh, M., Csordas, G., RamachandraRao, S., Sharma, K., Yule, D.I., Joseph, S.K., Hajnoczky, G., 2014. Isoform- and species-specific control of inositol 1,4,5-trisphosphate (IP3) receptors by reactive oxygen species. The Journal of biological chemistry. 289, 8170-81.

Bao, L., Taskin, E., Foster, M., Ray, B., Rosario, R., Ananthakrishnan, R., Howlett, S.E., Schmidt, A.M., Ramasamy, R., Coetzee, W.A., 2013. Alterations in ventricular K(ATP) channel properties during aging. Aging cell. 12, 167-76.

Bargmann, C.I., Horvitz, H.R., 1991. Chemosensory neurons with overlapping functions direct chemotaxis to multiple chemicals in C. elegans. Neuron. 7, 729-42.

Barnes, C.A., 1979. Memory deficits associated with senescence: a neurophysiological and behavioral study in the rat. Journal of comparative and physiological psychology. 93, 74-104.

Beckman, K.B., Ames, B.N., 1998. The free radical theory of aging matures. Physiological reviews. 78, 547-81.

Behringer, E.J., Shaw, R.L., Westcott, E.B., Socha, M.J., Segal, S.S., 2013. Aging impairs electrical conduction along endothelium of resistance arteries through enhanced $\mathrm{Ca} 2+$-activated $\mathrm{K}+$ channel activation. Arteriosclerosis, thrombosis, and vascular biology. 33, 1892-901.

Berridge, M.J., 1998. Neuronal calcium signaling. Neuron. 21, 13-26. 
Berridge, M.J., Lipp, P., Bootman, M.D., 2000. The versatility and universality of calcium signalling. Nature reviews. Molecular cell biology. 1, 11-21.

Bianchi, L., Kwok, S.M., Driscoll, M., Sesti, F., 2003. A potassium channel-MiRP complex controls neurosensory function in Caenorhabditis elegans. J Biol Chem. 278, $12415-24$.

Bliss, T.V., Collingridge, G.L., 1993. A synaptic model of memory: long-term potentiation in the hippocampus. Nature. 361, 31-9.

Bodhinathan, K., Kumar, A., Foster, T.C., 2010a. Redox sensitive calcium stores underlie enhanced after hyperpolarization of aged neurons: role for ryanodine receptor mediated calcium signaling. Journal of neurophysiology. 104, 2586-93.

Bodhinathan, K., Kumar, A., Foster, T.C., 2010b. Intracellular redox state alters NMDA receptor response during aging through $\mathrm{Ca} 2+$ /calmodulin-dependent protein kinase II. The Journal of neuroscience : the official journal of the Society for Neuroscience. 30, 1914-24.

Bokov, A., Chaudhuri, A., Richardson, A., 2004. The role of oxidative damage and stress in aging. Mechanisms of ageing and development. 125, 811-26.

Brown, L.A., Jin, J., Ferrell, D., Sadic, E., Obregon, D., Smith, A.J., Tan, J., Giunta, B., 2014. Efavirenz promotes beta-secretase expression and increased Abeta140,42 via oxidative stress and reduced microglial phagocytosis: implications for HIV associated neurocognitive disorders (HAND). PloS one. 9, e95500.

Bull, R., Marengo, J.J., Finkelstein, J.P., Behrens, M.I., Alvarez, O., 2003. SH oxidation coordinates subunits of rat brain ryanodine receptor channels activated by calcium and ATP. American journal of physiology. Cell physiology. 285, C119-28.

Bull, R., Finkelstein, J.P., Humeres, A., Behrens, M.I., Hidalgo, C., 2007. Effects of ATP, $\mathrm{Mg} 2+$, and redox agents on the $\mathrm{Ca} 2+$ dependence of RyR channels from rat brain cortex. American journal of physiology. Cell physiology. 293, C162-71.

Bull, R., Finkelstein, J.P., Galvez, J., Sanchez, G., Donoso, P., Behrens, M.I., Hidalgo, C., 2008. Ischemia enhances activation by $\mathrm{Ca} 2+$ and redox modification of ryanodine receptor channels from rat brain cortex. The Journal of neuroscience : the official journal of the Society for Neuroscience. 28, 9463-72.

Cai, S.Q., Sesti, F., 2009. Oxidation of a potassium channel causes progressive sensory function loss during aging. Nature Neuroscience. 12, 611-7.

Cai, Y., Xiong, K., Zhang, X.M., Cai, H., Luo, X.G., Feng, J.C., Clough, R.W., Struble, R.G., Patrylo, P.R., Chu, Y., Kordower, J.H., Yan, X.X., 2010. beta-Secretase-1 elevation in aged monkey and Alzheimer's disease human cerebral cortex occurs around the vasculature in partnership with multisystem axon terminal pathogenesis and beta-amyloid accumulation. The European journal of neuroscience. 32, 1223-38.

Che, H., Sun, L.H., Guo, F., Niu, H.F., Su, X.L., Bao, Y.N., Fu, Z.D., Liu, H.L., Hou, X., Yang, B.F., Ai, J., 2014. Expression of amyloid-associated miRNAs in both the forebrain cortex and hippocampus of middle-aged rat. Cellular physiology and biochemistry : international journal of experimental cellular physiology, biochemistry, and pharmacology. 33, 11-22.

Cheng, W.W., Tong, A., Flagg, T.P., Nichols, C.G., 2008. Random assembly of SUR subunits in K(ATP) channel complexes. Channels. 2, 34-8. 
Chung, Y.H., Joo, K.M., Kim, M.J., Cha, C.I., 2003. Age-related changes in the distribution of $\mathrm{Na}(\mathrm{v}) 1.1$ and $\mathrm{Na}(\mathrm{v}) 1.2$ in rat cerebellum. Neuroreport. 14, 841-5.

Clement, J.P.t., Kunjilwar, K., Gonzalez, G., Schwanstecher, M., Panten, U., AguilarBryan, L., Bryan, J., 1997. Association and stoichiometry of K(ATP) channel subunits. Neuron. 18, 827-38.

Cotella, D., Hernandez-Enriquez, B., Wu, X., Li, R., Pan, Z., Leveille, J., Link, C.D., Oddo, S., Sesti, F., 2012. Toxic role of k+ channel oxidation in Mammalian brain. The Journal of neuroscience : the official journal of the Society for Neuroscience. $32,4133-44$.

Dobarro, M., Orejana, L., Aguirre, N., Ramirez, M.J., 2013. Propranolol restores cognitive deficits and improves amyloid and Tau pathologies in a senescenceaccelerated mouse model. Neuropharmacology. 64, 137-44.

Donoso, P., Sanchez, G., Bull, R., Hidalgo, C., 2011. Modulation of cardiac ryanodine receptor activity by ROS and RNS. Frontiers in bioscience. 16, 553-67.

Droge, W., 2002. Free radicals in the physiological control of cell function. Physiological reviews. 82, 47-95.

Du, J., Tao-Cheng, J.H., Zerfas, P., McBain, C.J., 1998. The K+ channel, Kv2.1, is apposed to astrocytic processes and is associated with inhibitory postsynaptic membranes in hippocampal and cortical principal neurons and inhibitory interneurons. Neuroscience. 84, 37-48.

Du, Q., Jovanovic, S., Tulic, L., Sljivancanin, D., Jack, D.W., Zizic, V., Abdul, K.S., Tulic, I., Jovanovic, A., 2013. KATP channels are up-regulated with increasing age in human myometrium. Mechanisms of ageing and development. 134, 98-102.

Faber, E.S., 2010. Functional interplay between NMDA receptors, SK channels and voltage-gated $\mathrm{Ca} 2+$ channels regulates synaptic excitability in the medial prefrontal cortex. The Journal of physiology. 588, 1281-92.

Farajnia, S., Meijer, J.H., Michel, S., 2015. Age-related changes in large-conductance calcium-activated potassium channels in mammalian circadian clock neurons. Neurobiology of aging.

Favero, T.G., Zable, A.C., Abramson, J.J., 1995. Hydrogen peroxide stimulates the $\mathrm{Ca} 2+$ release channel from skeletal muscle sarcoplasmic reticulum. The Journal of biological chemistry. 270, 25557-63.

Feher, A., Broskova, Z., Bagi, Z., 2014. Age-related impairment of conducted dilation in human coronary arterioles. American journal of physiology. Heart and circulatory physiology. 306, H1595-601.

Fernandes, J., Marvao, P., Santos, A.I., Costa, P.F., 2001. Sodium channel currents in maturing acutely isolated rat hippocampal CA1 neurones. Brain research.

Developmental brain research. 132, 159-74.

Forman, H.J., Maiorino, M., Ursini, F., 2010. Signaling functions of reactive oxygen species. Biochemistry. 49, 835-42.

Foster, T.C., 1999. Involvement of hippocampal synaptic plasticity in age-related memory decline. Brain research. Brain research reviews. 30, 236-49.

Fukuda, K., Davies, S.S., Nakajima, T., Ong, B.H., Kupershmidt, S., Fessel, J., Amarnath, V., Anderson, M.E., Boyden, P.A., Viswanathan, P.C., Roberts, L.J., 2nd, Balser, J.R., 2005. Oxidative mediated lipid peroxidation recapitulates 
proarrhythmic effects on cardiac sodium channels. Circulation research. 97, 1262-9.

Fukumoto, H., Rosene, D.L., Moss, M.B., Raju, S., Hyman, B.T., Irizarry, M.C., 2004.

Beta-secretase activity increases with aging in human, monkey, and mouse brain. The American journal of pathology. 164, 719-25.

Furuichi, T., Furutama, D., Hakamata, Y., Nakai, J., Takeshima, H., Mikoshiba, K., 1994. Multiple types of ryanodine receptor/Ca2+ release channels are differentially expressed in rabbit brain. The Journal of neuroscience : the official journal of the Society for Neuroscience. 14, 4794-805.

Futatsugi, A., Kato, K., Ogura, H., Li, S.T., Nagata, E., Kuwajima, G., Tanaka, K., Itohara, S., Mikoshiba, K., 1999. Facilitation of NMDAR-independent LTP and spatial learning in mutant mice lacking ryanodine receptor type 3. Neuron. 24, 701-13.

Gems, D., Doonan, R., 2009. Antioxidant defense and aging in C. elegans: is the oxidative damage theory of aging wrong? Cell cycle. 8, 1681-7.

Gong, L., Gao, T.M., Huang, H., Tong, Z., 2000. Redox modulation of large conductance calcium-activated potassium channels in CA1 pyramidal neurons from adult rat hippocampus. Neuroscience letters. 286, 191-4.

Gong, L.W., Gao, T.M., Huang, H., Zhuang, Z.Y., Tong, Z., 2002. Transient forebrain ischemia induces persistent hyperactivity of large conductance $\mathrm{Ca} 2+$-activated potassium channels via oxidation modulation in rat hippocampal CA1 pyramidal neurons. The European journal of neuroscience. 15, 779-83.

Guglielmotto, M., Aragno, M., Autelli, R., Giliberto, L., Novo, E., Colombatto, S., Danni, O., Parola, M., Smith, M.A., Perry, G., Tamagno, E., Tabaton, M., 2009. The upregulation of BACE1 mediated by hypoxia and ischemic injury: role of oxidative stress and HIF1alpha. Journal of neurochemistry. 108, 1045-56.

Guglielmotto, M., Giliberto, L., Tamagno, E., Tabaton, M., 2010. Oxidative stress mediates the pathogenic effect of different Alzheimer's disease risk factors. Frontiers in aging neuroscience. 2, 3.

Hakamata, Y., Nakai, J., Takeshima, H., Imoto, K., 1992. Primary structure and distribution of a novel ryanodine receptor/calcium release channel from rabbit brain. FEBS letters. 312, 229-35.

Hanna, A.D., Lam, A., Thekkedam, C., Gallant, E.M., Beard, N.A., Dulhunty, A.F., 2014. Cardiac ryanodine receptor activation by a high $\mathrm{Ca}(2)(+)$ store load is reversed in a reducing cytoplasmic redox environment. Journal of cell science. 127, 4531-41.

Harman, D., 1956. Aging: a theory based on free radical and radiation chemistry. Journal of gerontology. 11, 298-300.

Hidalgo, C., Bull, R., Behrens, M.I., Donoso, P., 2004. Redox regulation of RyRmediated $\mathrm{Ca} 2+$ release in muscle and neurons. Biological research. 37, 539-52.

Hidalgo, C., Carrasco, M.A., Munoz, P., Nunez, M.T., 2007. A role for reactive oxygen/nitrogen species and iron on neuronal synaptic plasticity. Antioxidants \& redox signaling. 9, 245-55.

Hille, B., 2001. Ionic channels of excitable membranes, Vol., Sinauer Associates., Sunderland MA.

Hsu, K.S., Huang, C.C., Liang, Y.C., Wu, H.M., Chen, Y.L., Lo, S.W., Ho, W.C., 2002. Alterations in the balance of protein kinase and phosphatase activities and age- 
related impairments of synaptic transmission and long-term potentiation. Hippocampus. 12, 787-802.

Hu, H., Shao, L.R., Chavoshy, S., Gu, N., Trieb, M., Behrens, R., Laake, P., Pongs, O., Knaus, H.G., Ottersen, O.P., Storm, J.F., 2001. Presynaptic Ca2+-activated K+ channels in glutamatergic hippocampal terminals and their role in spike repolarization and regulation of transmitter release. The Journal of neuroscience : the official journal of the Society for Neuroscience. 21, 9585-97.

Hu, X., Zhou, X., He, W., Yang, J., Xiong, W., Wong, P., Wilson, C.G., Yan, R., 2010. BACE1 deficiency causes altered neuronal activity and neurodegeneration. The Journal of neuroscience : the official journal of the Society for Neuroscience. 30, 8819-29.

Hu, X.Q., Huang, X., Xiao, D., Zhang, L., 2015. Direct effect of chronic hypoxia in suppressing large conductance $\mathrm{Ca}$-activated $\mathrm{K}$ channel activity in ovine uterine arteries via increasing oxidative stress. The Journal of physiology.

Huang, X., Du, Y., Yang, P., Lin, S., Xi, Y., Yang, Z., Ma, A., 2015. Age-dependent alterations of voltage-gated $\mathrm{Na}$ channel isoforms in rat sinoatrial node. Mechanisms of ageing and development.

Inagaki, N., Gonoi, T., Clement, J.P.t., Namba, N., Inazawa, J., Gonzalez, G., AguilarBryan, L., Seino, S., Bryan, J., 1995. Reconstitution of IKATP: an inward rectifier subunit plus the sulfonylurea receptor. Science. 270, 1166-70.

Johnston, D., Williams, S., Jaffe, D., Gray, R., 1992. NMDA-receptor-independent longterm potentiation. Annual review of physiology. 54, 489-505.

Kaczmarek, L.K., 2006. Non-conducting functions of voltage-gated ion channels. Nature reviews. Neuroscience. 7, 761-71.

Kassmann, M., Hansel, A., Leipold, E., Birkenbeil, J., Lu, S.Q., Hoshi, T., Heinemann, S.H., 2008. Oxidation of multiple methionine residues impairs rapid sodium channel inactivation. Pflugers Archiv : European journal of physiology. 456, 108595.

Kern, A., Roempp, B., Prager, K., Walter, J., Behl, C., 2006. Down-regulation of endogenous amyloid precursor protein processing due to cellular aging. The Journal of biological chemistry. 281, 2405-13.

Kim, D.Y., Carey, B.W., Wang, H., Ingano, L.A., Binshtok, A.M., Wertz, M.H., Pettingell, W.H., He, P., Lee, V.M., Woolf, C.J., Kovacs, D.M., 2007. BACE1 regulates voltage-gated sodium channels and neuronal activity. Nature cell biology. 9, 75564.

Kim, D.Y., Gersbacher, M.T., Inquimbert, P., Kovacs, D.M., 2011. Reduced sodium channel $\mathrm{Na}(\mathrm{v}) 1.1$ levels in BACE1-null mice. The Journal of biological chemistry. 286, 8106-16.

Kizuka, Y., Nakano, M., Kitazume, S., Saito, T., Saido, T.C., Taniguchi, N., 2016. Bisecting GlcNAc modification stabilizes BACE1 protein under oxidative stress conditions. The Biochemical journal. 473, 21-30.

Kregel, K.C., Zhang, H.J., 2007. An integrated view of oxidative stress in aging: basic mechanisms, functional effects, and pathological considerations. American journal of physiology. Regulatory, integrative and comparative physiology. 292, R18-36. 
Kumar, A., Foster, T.C., 2004. Enhanced long-term potentiation during aging is masked by processes involving intracellular calcium stores. Journal of neurophysiology. 91, 2437-44.

Kumar, A., Bodhinathan, K., Foster, T.C., 2009. Susceptibility to Calcium Dysregulation during Brain Aging. Frontiers in aging neuroscience. 1, 2.

Kwak, Y.D., Wang, R., Li, J.J., Zhang, Y.W., Xu, H., Liao, F.F., 2011. Differential regulation of BACE1 expression by oxidative and nitrosative signals. Molecular neurodegeneration. 6, 17.

Lai, F.A., Dent, M., Wickenden, C., Xu, L., Kumari, G., Misra, M., Lee, H.B., Sar, M., Meissner, G., 1992. Expression of a cardiac $\mathrm{Ca}(2+)$-release channel isoform in mammalian brain. The Biochemical journal. 288 ( Pt 2), 553-64.

Landfield, P.W., McGaugh, J.L., Lynch, G., 1978. Impaired synaptic potentiation processes in the hippocampus of aged, memory-deficient rats. Brain research. 150, 85-101.

Lanner, J.T., Georgiou, D.K., Joshi, A.D., Hamilton, S.L., 2010. Ryanodine receptors: structure, expression, molecular details, and function in calcium release. Cold Spring Harbor perspectives in biology. 2, a003996.

Liao, Y., Kristiansen, A.M., Oksvold, C.P., Tuvnes, F.A., Gu, N., Runden-Pran, E., Ruth, P., Sausbier, M., Storm, J.F., 2010. Neuronal Ca2+-activated K+ channels limit brain infarction and promote survival. PloS one. 5, e15601.

Liu, D., Pitta, M., Lee, J.H., Ray, B., Lahiri, D.K., Furukawa, K., Mughal, M., Jiang, H., Villarreal, J., Cutler, R.G., Greig, N.H., Mattson, M.P., 2010. The KATP channel activator diazoxide ameliorates amyloid-beta and tau pathologies and improves memory in the 3xTgAD mouse model of Alzheimer's disease. Journal of Alzheimer's disease : JAD. 22, 443-57.

Maglioni, S., Schiavi, A., Runci, A., Shaik, A., Ventura, N., 2014. Mitochondrial stress extends lifespan in C. elegans through neuronal hormesis. Experimental gerontology. 56, 89-98.

Maher, P., 2006. Redox Control of Neural Function: Background, Mechanisms, and Significance. Antioxidants \& redox signaling. 8, 1941-1970.

Malenka, R.C., Bear, M.F., 2004. LTP and LTD: an embarrassment of riches. Neuron. 44, 5-21.

Marengo, J.J., Hidalgo, C., Bull, R., 1998. Sulfhydryl oxidation modifies the calcium dependence of ryanodine-sensitive calcium channels of excitable cells. Biophysical journal. 74, 1263-77.

McCord, M.C., Aizenman, E., 2013. Convergent Ca2+ and Zn2+ signaling regulates apoptotic Kv2.1 K+ currents. Proceedings of the National Academy of Sciences of the United States of America. 110, 13988-93.

McNaughton, B.L., Barnes, C.A., Rao, G., Baldwin, J., Rasmussen, M., 1986. Longterm enhancement of hippocampal synaptic transmission and the acquisition of spatial information. The Journal of neuroscience : the official journal of the Society for Neuroscience. 6, 563-71.

McTaggart, J.S., Clark, R.H., Ashcroft, F.M., 2010. The role of the KATP channel in glucose homeostasis in health and disease: more than meets the islet. The Journal of physiology. 588, 3201-9. 
Miners, J.S., van Helmond, Z., Kehoe, P.G., Love, S., 2010. Changes with age in the activities of beta-secretase and the Abeta-degrading enzymes neprilysin, insulindegrading enzyme and angiotensin-converting enzyme. Brain pathology. 20, 794-802.

Minniti, A.N., Cataldo, R., Trigo, C., Vasquez, L., Mujica, P., Leighton, F., Inestrosa, N.C., Aldunate, R., 2009. Methionine sulfoxide reductase A expression is regulated by the DAF-16/FOXO pathway in Caenorhabditis elegans. Aging cell. 8, 690-705.

Misonou, H., Menegola, M., Buchwalder, L., Park, E.W., Meredith, A., Rhodes, K.J., Aldrich, R.W., Trimmer, J.S., 2006. Immunolocalization of the Ca2+-activated K+ channel Slo1 in axons and nerve terminals of mammalian brain and cultured neurons. The Journal of comparative neurology. 496, 289-302.

Mockett, R.J., Sohal, B.H., Sohal, R.S., 2010. Expression of multiple copies of mitochondrially targeted catalase or genomic Mn superoxide dismutase transgenes does not extend the life span of Drosophila melanogaster. Free radical biology \& medicine. 49, 2028-31.

Moosmang, S., Haider, N., Klugbauer, N., Adelsberger, H., Langwieser, N., Muller, J., Stiess, M., Marais, E., Schulla, V., Lacinova, L., Goebbels, S., Nave, K.A., Storm, D.R., Hofmann, F., Kleppisch, T., 2005. Role of hippocampal Cav1.2 Ca2+ channels in NMDA receptor-independent synaptic plasticity and spatial memory. The Journal of neuroscience : the official journal of the Society for Neuroscience. 25, 9883-92.

Morris, R.G., Anderson, E., Lynch, G.S., Baudry, M., 1986. Selective impairment of learning and blockade of long-term potentiation by an $\mathrm{N}$-methyl-D-aspartate receptor antagonist, AP5. Nature. 319, 774-6.

Mouton-Liger, F., Paquet, C., Dumurgier, J., Bouras, C., Pradier, L., Gray, F., Hugon, J., 2012. Oxidative stress increases BACE1 protein levels through activation of the PKR-elF2alpha pathway. Biochimica et biophysica acta. 1822, 885-96.

Murakoshi, H., Trimmer, J.S., 1999. Identification of the Kv2.1 K+ channel as a major component of the delayed rectifier $\mathrm{K}+$ current in rat hippocampal neurons. The Journal of neuroscience : the official journal of the Society for Neuroscience. 19, 1728-35.

Nakajima, T., Davies, S.S., Matafonova, E., Potet, F., Amarnath, V., Tallman, K.A., Serwa, R.A., Porter, N.A., Balser, J.R., Kupershmidt, S., Roberts, L.J., 3rd, 2010. Selective gamma-ketoaldehyde scavengers protect Nav1.5 from oxidant-induced inactivation. Journal of molecular and cellular cardiology. 48, 352-9.

Norris, C.A., He, K., Springer, M.G., Hartnett, K.A., Horn, J.P., Aizenman, E., 2012. Regulation of neuronal proapoptotic potassium currents by the hepatitis $C$ virus nonstructural protein $5 \mathrm{~A}$. The Journal of neuroscience : the official journal of the Society for Neuroscience. 32, 8865-70.

Norris, C.M., Halpain, S., Foster, T.C., 1998. Reversal of age-related alterations in synaptic plasticity by blockade of L-type $\mathrm{Ca} 2+$ channels. The Journal of neuroscience : the official journal of the Society for Neuroscience. 18, 3171-9.

Obermair, G.J., Kaufmann, W.A., Knaus, H.G., Flucher, B.E., 2003. The small conductance $\mathrm{Ca} 2+-$ activated $\mathrm{K}+$ channel SK3 is localized in nerve terminals of 
excitatory synapses of cultured mouse hippocampal neurons. The European journal of neuroscience. 17, 721-31.

Oda, T., Yang, Y., Uchinoumi, H., Thomas, D.D., Chen-Izu, Y., Kato, T., Yamamoto, T., Yano, M., Cornea, R.L., Bers, D.M., 2015. Oxidation of ryanodine receptor (RyR) and calmodulin enhance Ca release and pathologically alter, RyR structure and calmodulin affinity. Journal of molecular and cellular cardiology. 85, 240-8.

Oh, M.M., Oliveira, F.A., Disterhoft, J.F., 2010. Learning and aging related changes in intrinsic neuronal excitability. Frontiers in aging neuroscience. 2, 2.

Paula-Lima, A.C., Adasme, T., Hidalgo, C., 2014. Contribution of Ca2+ release channels to hippocampal synaptic plasticity and spatial memory: potential redox modulation. Antioxidants \& redox signaling. 21, 892-914.

Power, J.M., Wu, W.W., Sametsky, E., Oh, M.M., Disterhoft, J.F., 2002. Age-related enhancement of the slow outward calcium-activated potassium current in hippocampal CA1 pyramidal neurons in vitro. The Journal of neuroscience : the official journal of the Society for Neuroscience. 22, 7234-43.

Rana, A., Goyal, N., Ahlawat, A., Jamwal, S., Reddy, B.V., Sharma, S., 2015. Mechanisms involved in attenuated cardio-protective role of ischemic preconditioning in metabolic disorders. Perfusion. 30, 94-105.

Randall, A.D., Booth, C., Brown, J.T., 2012. Age-related changes to $\mathrm{Na}+$ channel gating contribute to modified intrinsic neuronal excitability. Neurobiology of aging. 33, 2715-20.

Raveaud, S., Verdetti, J., Faury, G., 2009. Nicorandil protects ATP-sensitive potassium channels against oxidation-induced dysfunction in cardiomyocytes of aging rats. Biogerontology. 10, 537-47.

Redman, P.T., He, K., Hartnett, K.A., Jefferson, B.S., Hu, L., Rosenberg, P.A., Levitan, E.S., Aizenman, E., 2007. Apoptotic surge of potassium currents is mediated by p38 phosphorylation of Kv2.1. Proceedings of the National Academy of Sciences of the United States of America. 104, 3568-73.

Redman, P.T., Hartnett, K.A., Aras, M.A., Levitan, E.S., Aizenman, E., 2009. Regulation of apoptotic potassium currents by coordinated zinc-dependent signalling. The Journal of physiology. 587, 4393-404.

Ristow, M., Schmeisser, S., 2011. Extending life span by increasing oxidative stress. Free radical biology \& medicine. 51, 327-36.

Robillard, J.M., Gordon, G.R., Choi, H.B., Christie, B.R., MacVicar, B.A., 2011. Glutathione restores the mechanism of synaptic plasticity in aged mice to that of the adult. PloS one. 6, e20676.

Rojas, P., Garst-Orozco, J., Baban, B., de Santiago-Castillo, J.A., Covarrubias, M., Salkoff, L., 2008. Cumulative activation of voltage-dependent KVS-1 potassium channels. The Journal of neuroscience : the official journal of the Society for Neuroscience. 28, 757-65.

Runden-Pran, E., Haug, F.M., Storm, J.F., Ottersen, O.P., 2002. BK channel activity determines the extent of cell degeneration after oxygen and glucose deprivation: a study in organotypical hippocampal slice cultures. Neuroscience. 112, 277-88.

Santarelli, L.C., Wassef, R., Heinemann, S.H., Hoshi, T., 2006. Three methionine residues located within the regulator of conductance for $\mathrm{K}+(\mathrm{RCK})$ domains 
confer oxidative sensitivity to large-conductance $\mathrm{Ca} 2+$-activated $\mathrm{K}+$ channels. The Journal of physiology. 571, 329-48.

Sesti, F., Liu, S., Cai, S.Q., 2010. Oxidation of potassium channels by ROS: a general mechanism of aging and neurodegeneration? Trends in cell biology. 20, 45-51.

Sharp, A.H., McPherson, P.S., Dawson, T.M., Aoki, C., Campbell, K.P., Snyder, S.H., 1993. Differential immunohistochemical localization of inositol 1,4,5trisphosphate- and ryanodine-sensitive $\mathrm{Ca} 2+$ release channels in rat brain. The Journal of neuroscience : the official journal of the Society for Neuroscience. 13, 3051-63.

Soh, H., Jung, W., Uhm, D.Y., Chung, S., 2001. Modulation of large conductance calcium-activated potassium channels from rat hippocampal neurons by glutathione. Neuroscience letters. 298, 115-8.

Sohal, R.S., Weindruch, R., 1996. Oxidative stress, caloric restriction, and aging. Science. 273, 59-63.

Sohal, R.S., Orr, W.C., 2012. The redox stress hypothesis of aging. Free radical biology \& medicine. 52, 539-55.

Solas, M., Aisa, B., Tordera, R.M., Mugueta, M.C., Ramirez, M.J., 2013. Stress contributes to the development of central insulin resistance during aging: implications for Alzheimer's disease. Biochimica et biophysica acta. 1832, 23329.

Takeshima, H., Nishimura, S., Matsumoto, T., Ishida, H., Kangawa, K., Minamino, N., Matsuo, H., Ueda, M., Hanaoka, M., Hirose, T., et al., 1989. Primary structure and expression from complementary DNA of skeletal muscle ryanodine receptor. Nature. 339, 439-45.

Tamagno, E., Bardini, P., Obbili, A., Vitali, A., Borghi, R., Zaccheo, D., Pronzato, M.A., Danni, O., Smith, M.A., Perry, G., Tabaton, M., 2002. Oxidative stress increases expression and activity of BACE in NT2 neurons. Neurobiology of disease. 10, 279-88.

Tan, J.L., Li, Q.X., Ciccotosto, G.D., Crouch, P.J., Culvenor, J.G., White, A.R., Evin, G., 2013. Mild oxidative stress induces redistribution of BACE1 in non-apoptotic conditions and promotes the amyloidogenic processing of Alzheimer's disease amyloid precursor protein. PloS one. 8, e61246.

Tang, X.D., Garcia, M.L., Heinemann, S.H., Hoshi, T., 2004. Reactive oxygen species impair Slo1 BK channel function by altering cysteine-mediated calcium sensing. Nature structural \& molecular biology. 11, 171-8.

Thibault, O., Landfield, P.W., 1996. Increase in single L-type calcium channels in hippocampal neurons during aging. Science. 272, 1017-20.

Toyoda, K., Fujii, K., Takata, Y., Ibayashi, S., Kitazono, T., Nagao, T., Fujikawa, M., Fujishima, M., 1997. Age-related changes in response of brain stem vessels to opening of ATP-sensitive potassium channels. Stroke; a journal of cerebral circulation. 28, 171-5.

Tricarico, D., Camerino, D.C., 1994. ATP-sensitive K+ channels of skeletal muscle fibers from young adult and aged rats: possible involvement of thiol-dependent redox mechanisms in the age-related modifications of their biophysical and pharmacological properties. Molecular pharmacology. 46, 754-61. 
Tricarico, D., Petruzzi, R., Camerino, D.C., 1997. Changes of the biophysical properties of calcium-activated potassium channels of rat skeletal muscle fibres during aging. Pflugers Archiv : European journal of physiology. 434, 822-9.

Trimmer, J.S., 1991. Immunological identification and characterization of a delayed rectifier $\mathrm{K}+$ channel polypeptide in rat brain. Proceedings of the National Academy of Sciences of the United States of America. 88, 10764-8.

Trimmer, J.S., 1993. Expression of Kv2.1 delayed rectifier K+ channel isoforms in the developing rat brain. FEBS letters. 324, 205-10.

Trimmer, J.S., Rhodes, K.J., 2004. Localization of voltage-gated ion channels in mammalian brain. Annual review of physiology. 66, 477-519.

Turner, R.W., Kruskic, M., Teves, M., Scheidl-Yee, T., Hameed, S., Zamponi, G.W., 2015. Neuronal expression of the intermediate conductance calcium-activated potassium channel KCa3.1 in the mammalian central nervous system. Pflugers Archiv : European journal of physiology. 467, 311-28.

Veal, E., Day, A., 2011. Hydrogen peroxide as a signaling molecule. Antioxidants \& redox signaling. 15, 147-51.

Vergara, C., Ramirez, B.U., 1997. Age-dependent expression of the apamin-sensitive calcium-activated $\mathrm{K}+$ channel in fast and slow rat skeletal muscle. Experimental neurology. 146, 282-5.

Vergara, C., Latorre, R., Marrion, N.V., Adelman, J.P., 1998. Calcium-activated potassium channels. Current opinion in neurobiology. 8, 321-9.

Verkhratsky, A., 2002. The endoplasmic reticulum and neuronal calcium signalling. Cell Calcium. 32, 393-404.

Verkhratsky, A., Petersen, O.H., 2002. The endoplasmic reticulum as an integrating signalling organelle: from neuronal signalling to neuronal death. European journal of pharmacology. 447, 141-54.

Virgili, N., Mancera, P., Wappenhans, B., Sorrosal, G., Biber, K., Pugliese, M., Espinosa-Parrilla, J.F., 2013. K(ATP) channel opener diazoxide prevents neurodegeneration: a new mechanism of action via antioxidative pathway activation. PloS one. 8, e75189.

Voss, A.A., Lango, J., Ernst-Russell, M., Morin, D., Pessah, I.N., 2004. Identification of hyperreactive cysteines within ryanodine receptor type 1 by mass spectrometry. The Journal of biological chemistry. 279, 34514-20.

Wu, J., Rowan, M.J., Anwyl, R., 2004. An NMDAR-independent LTP mediated by group II metabotropic glutamate receptors and p42/44 MAP kinase in the dentate gyrus in vitro. Neuropharmacology. 46, 311-7.

Wu, X., Hernandez-Enriquez, B., Banas, M., Xu, R., Sesti, F., 2013. Molecular Mechanisms Underlying the Apoptotic Effect of KCNB1 K+ Channel Oxidation. The Journal of biological chemistry. 288, 4128-34.

Wu, X.Y., Li, J.Z., Guo, J.Z., Hou, B.Y., 2012. Ameliorative effects of curculigoside from Curculigo orchioides Gaertn on learning and memory in aged rats. Molecules. 17, 10108-18.

Wu, Y., Wu, Z., Butko, P., Christen, Y., Lambert, M.P., Klein, W.L., Link, C.D., Luo, Y., 2006. Amyloid-beta-induced pathological behaviors are suppressed by Ginkgo biloba extract EGb 761 and ginkgolides in transgenic Caenorhabditis elegans. 
The Journal of neuroscience : the official journal of the Society for Neuroscience. 26, 13102-13.

Xiong, K., Cai, H., Luo, X.G., Struble, R.G., Clough, R.W., Yan, X.X., 2007. Mitochondrial respiratory inhibition and oxidative stress elevate beta-secretase (BACE1) proteins and activity in vivo in the rat retina. Experimental brain research. 181, 435-46.

Yamada, M., Isomoto, S., Matsumoto, S., Kondo, C., Shindo, T., Horio, Y., Kurachi, Y., 1997. Sulphonylurea receptor $2 \mathrm{~B}$ and Kir6.1 form a sulphonylurea-sensitive but ATP-insensitive K+ channel. The Journal of physiology. 499 ( Pt 3), 715-20.

Yang, Y.J., Wu, P.F., Long, L.H., Yu, D.F., Wu, W.N., Hu, Z.L., Fu, H., Xie, N., Jin, Y., Ni, L., Wang, J.Z., Wang, F., Chen, J.G., 2010. Reversal of aging-associated hippocampal synaptic plasticity deficits by reductants via regulation of thiol redox and NMDA receptor function. Aging cell. 9, 709-21.

Ye, H., Jalini, S., Mylvaganam, S., Carlen, P., 2010. Activation of large-conductance $\mathrm{Ca}(2+)$-activated $\mathrm{K}(+)$ channels depresses basal synaptic transmission in the hippocampal CA1 area in APP (swe/ind) TgCRND8 mice. Neurobiology of aging. 31, 591-604.

Zeng, X.H., Xia, X.M., Lingle, C.J., 2003. Redox-sensitive extracellular gates formed by auxiliary beta subunits of calcium-activated potassium channels. Nature structural biology. 10, 448-54.

Zhang, G., Xu, R., Heinemann, S.H., Hoshi, T., 2006. Cysteine oxidation and rundown of large-conductance $\mathrm{Ca} 2+$-dependent $\mathrm{K}+$ channels. Biochemical and biophysical research communications. 342, 1389-95.

Zhou, M.H., Yang, G., Jiao, S., Hu, C.L., Mei, Y.A., 2012. Cholesterol enhances neuron susceptibility to apoptotic stimuli via cAMP/PKA/CREB-dependent up-regulation of Kv2.1. Journal of neurochemistry. 120, 502-14. 


\section{Figure Legends}

\section{Figure 1 Different modes of modulation of KCNB1 by ROS}

A) Oxidants promote cross-link of KCNB1 subunits to each other via the formation of disulfide bridges between several cysteines, including cys73 and cys710 (inset). As a consequence, KCNB1 oligomers transiently accumulate in the plasma membrane where their presence activates Src/JNK kinases signaling. This "death" pathway leads to mitochondria destabilization and oxidative stress.

B) ROS also induce elevation of cytoplasmic $\mathrm{Ca}^{2+}$ and $\mathrm{Zn}^{2+}$ that contributes to apoptosis via a phosphorylation-mediated surge of KCNB1 channels to the plasma membrane. $\mathrm{Zn}^{2+}$ activates ASK-1/p38 signaling and independently, Src tyrosine kinases.

Phosphorylation of KCNB1 at ser800 and tyr124 (inset) favours the interaction between the channel and the SNARE family protein syntaxin. $\mathrm{Ca}^{2+}$ activates CaMKII kinase which in turn acts to modulate the interaction of phopshorylated KCNB1 with syntaxin.

Figure 2 Major pathways leading to intracellular $\mathrm{Ca}^{2+}$ increase during LTP in the hippocampus

A) In young hippocampi, the NMDAR provides the major pathway underlying the transient increase in cytosolic calcium that potentiates the AMPA receptor component of synaptic strength. Along with this NMDAR-dependent mechanism, two NMDARindependent mechanisms: 1) opening of VDCCs and 2) release of calcium from ICS through opening of RyRs (CICR) and $\mathrm{IP}_{3} \mathrm{R}$ activation via metabotropic glutamate receptors, further contribute to elevate intracellular calcium. 
B) In aging hippocampi, the increased oxidation in the cells alters the equilibrium between the NMDAR-dependent and NMDAR-independent mechanisms by causing a progressive impairment of the NMDAR-dependent mechanism and a simultaneous potentiation of the CICR mechanism via direct oxidation of the RyRs. The surplus of calcium that follows, activates SK channels, which lower susceptibility to LTP induction by dampening the excitability of the membrane.

Figure 3 Nav1.1 current density depends on the activity of BACE1 and $y$ secretases

A) Under normal conditions, sequential cleavage of Nav $\beta 2$ by BACE1 and $\gamma$-secretases leads to the release of a soluble intracellular domain $\beta 2$-ICD. This domain regulates the synthesis of Nav1.1 mRNA and protein levels acting at the transcriptional level.

B) The oxidative conditions present in aging neurons act to upregulate both the activity and expression of BACE1, which results in augmented Nav1.1 transcription and translation. However, the newly synthesized channels fail to properly translocate to the plasma membrane, resulting in reduction of Nav1.1 current. This suggests that BACE1 may act as a indirect mechanism to decrease sodium current density and consequently reduce neuronal excitability during aging, but this hypothesis awaits further experimental support. 
Figure 1

A Direct Oxidation

\section{B Indirect Oxidation}

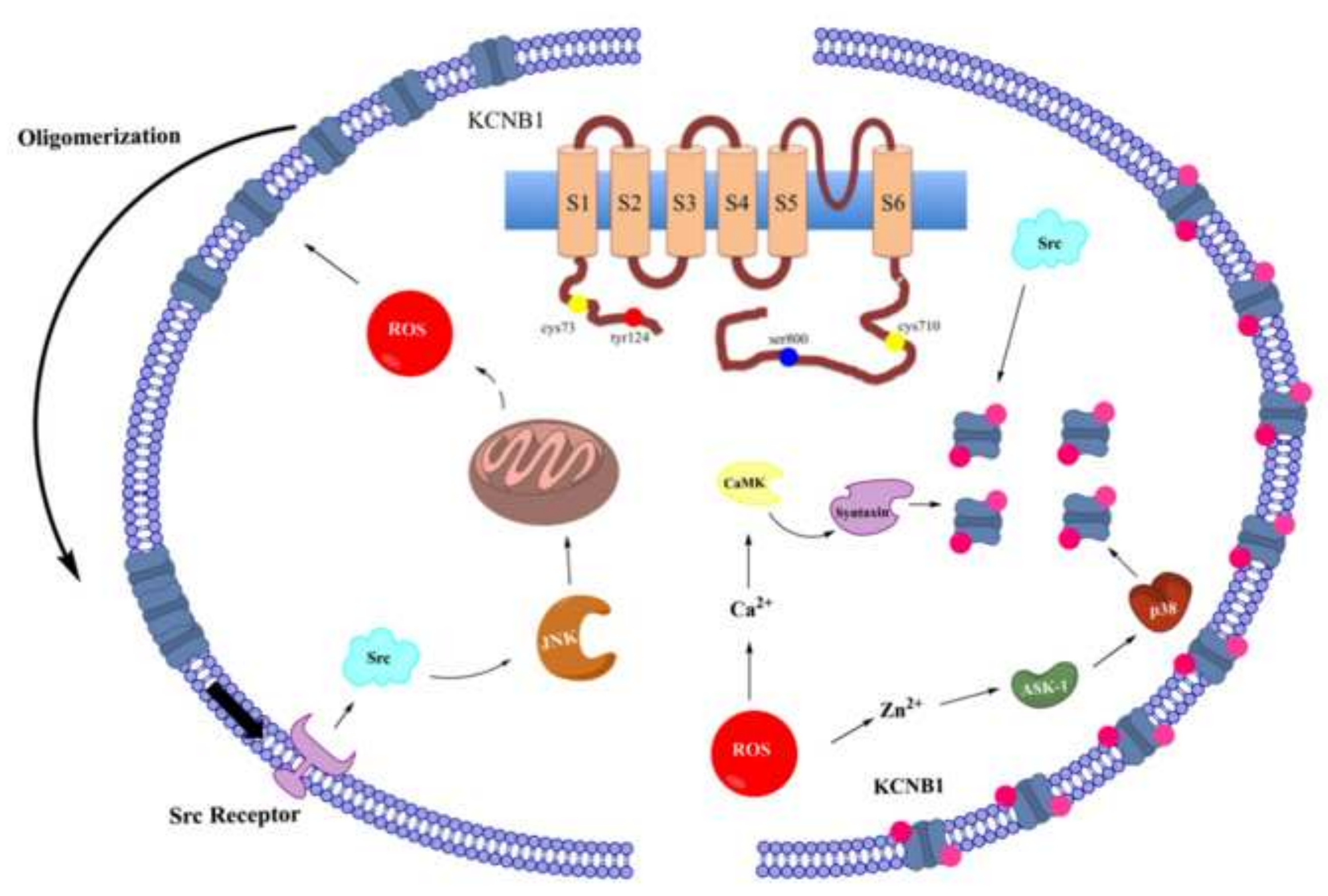




\section{Figure 2}
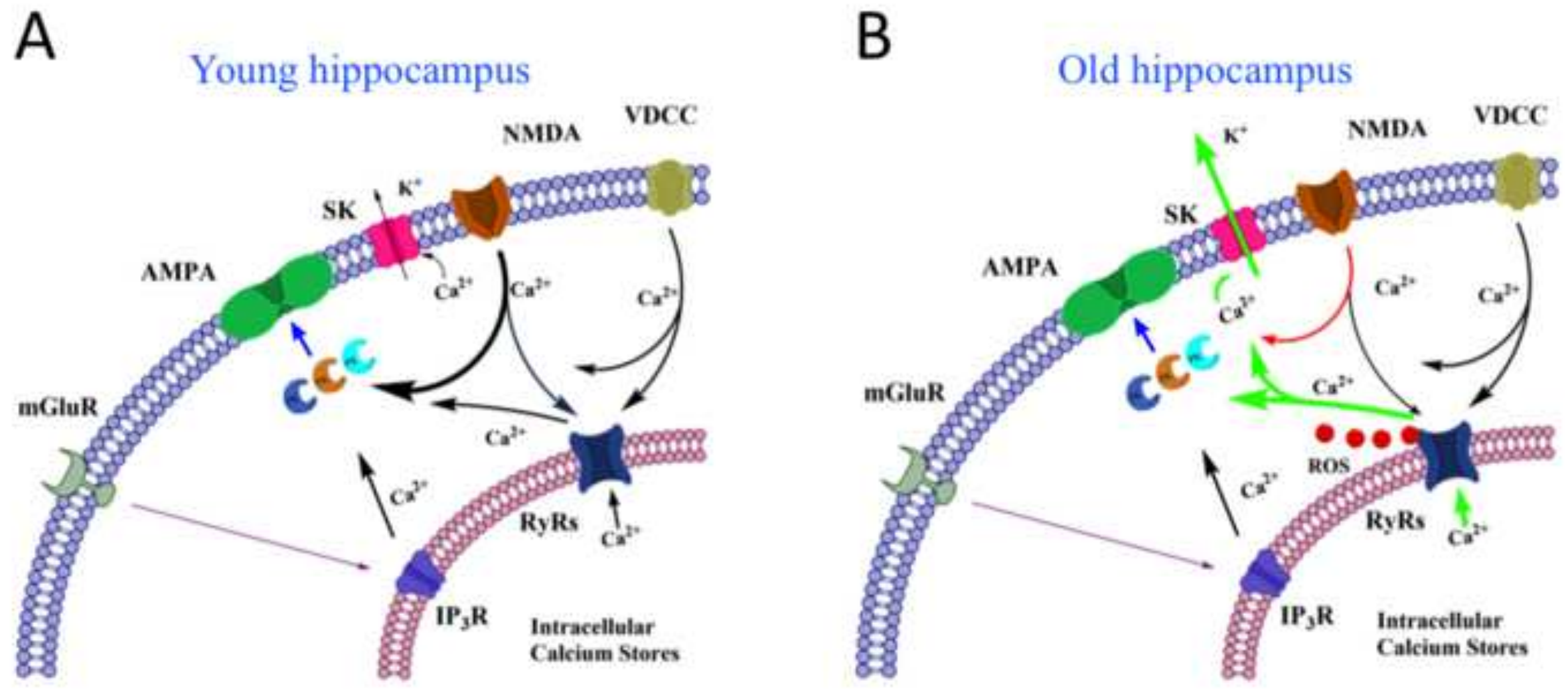
A

Young brain

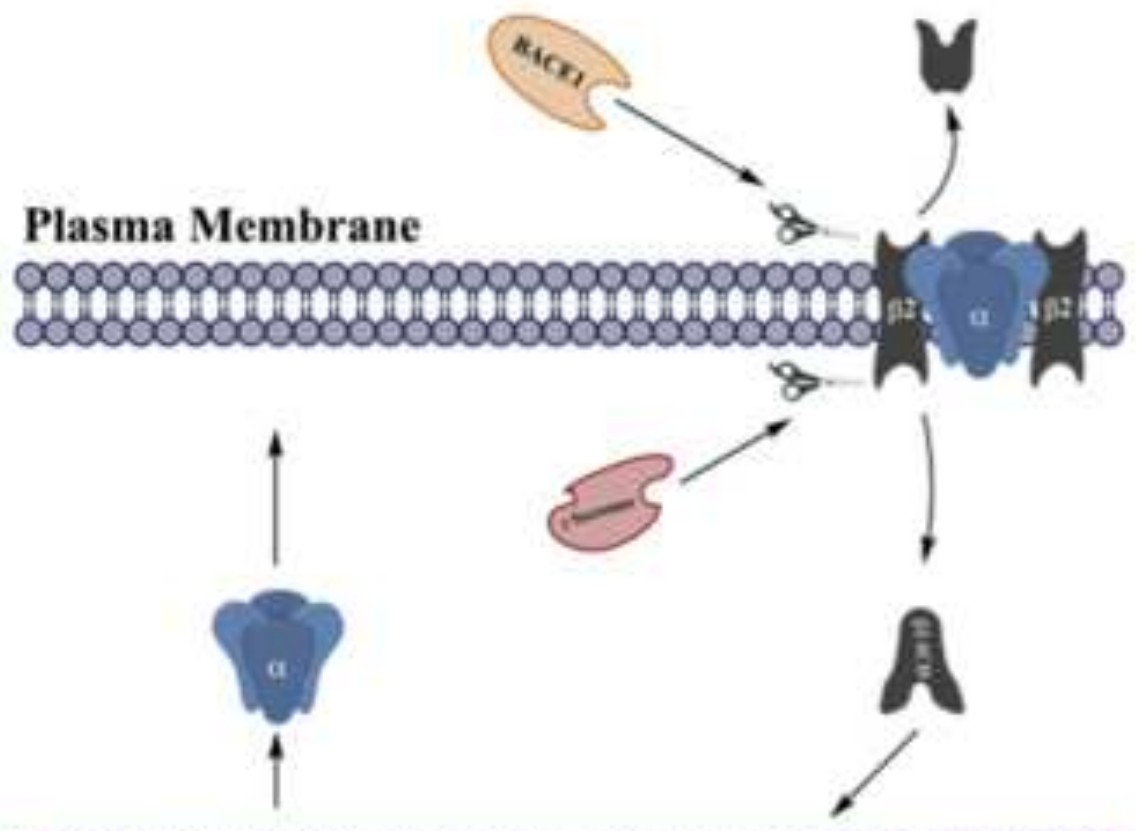

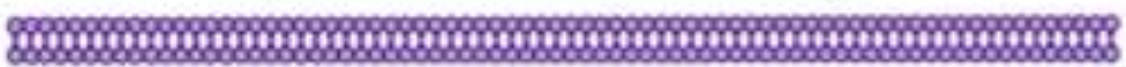

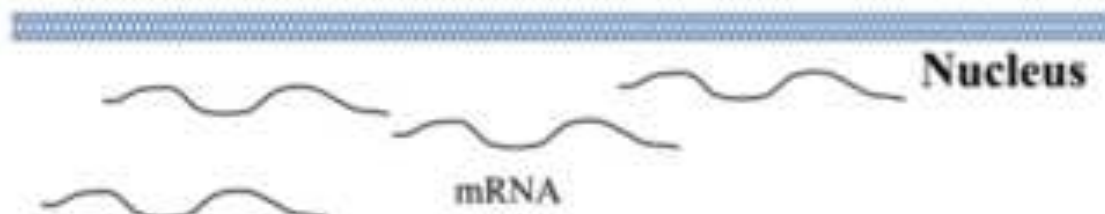

B

Old brain

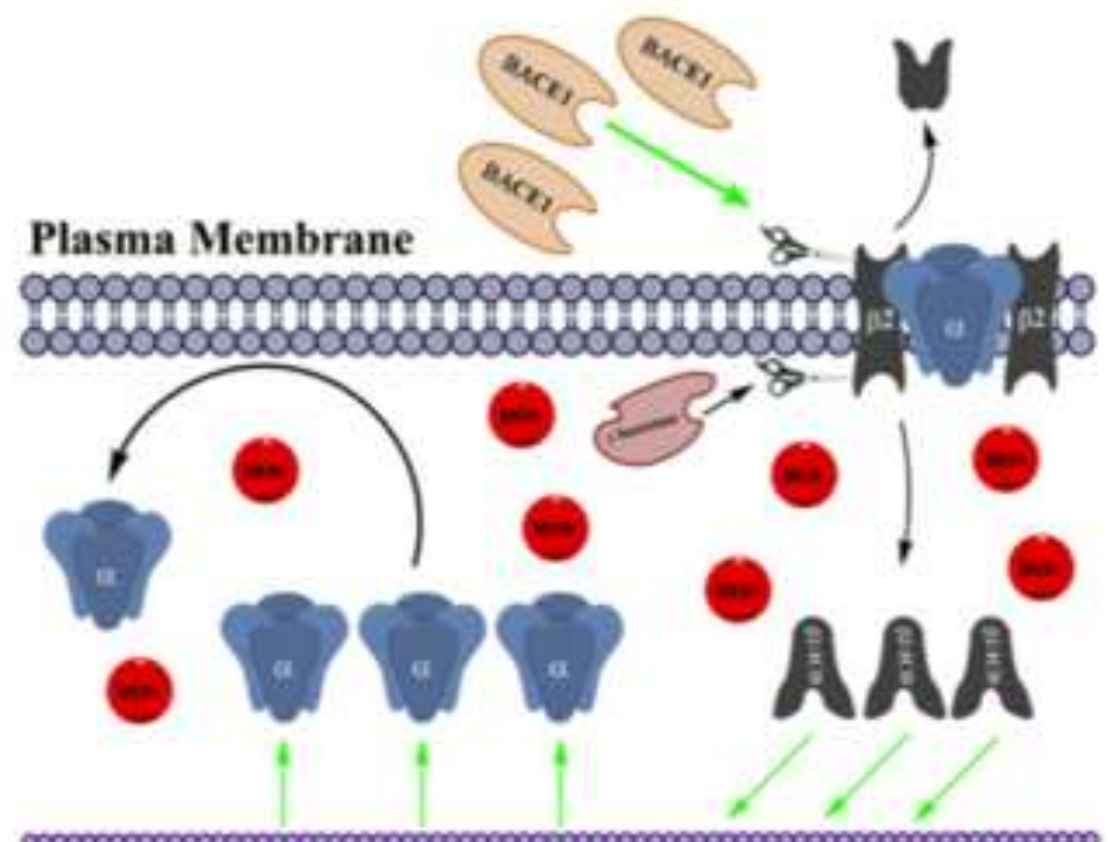

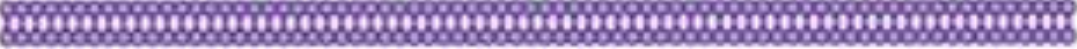

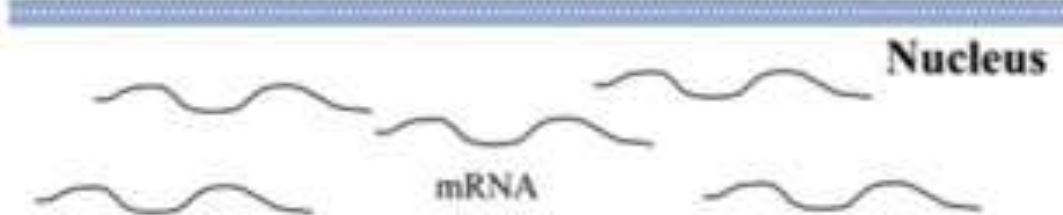

